
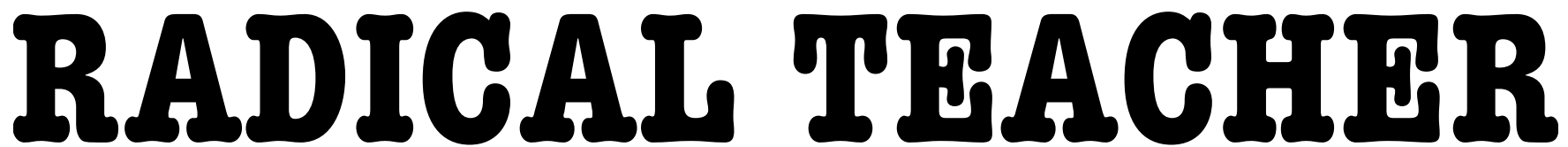

A SOCIALIST, FEMINIST, AND ANTI-RACIST JOURNAL ON THE THEORY AND PRACTICE OF TEACHING

\title{
Design Thinking, Collaborative Innovation, and Neoliberal Disappointment: Cruel Optimism in the History and Future of Higher Education
}

by Kate Catterall, Julia Mickenberg, and Richard Reddick

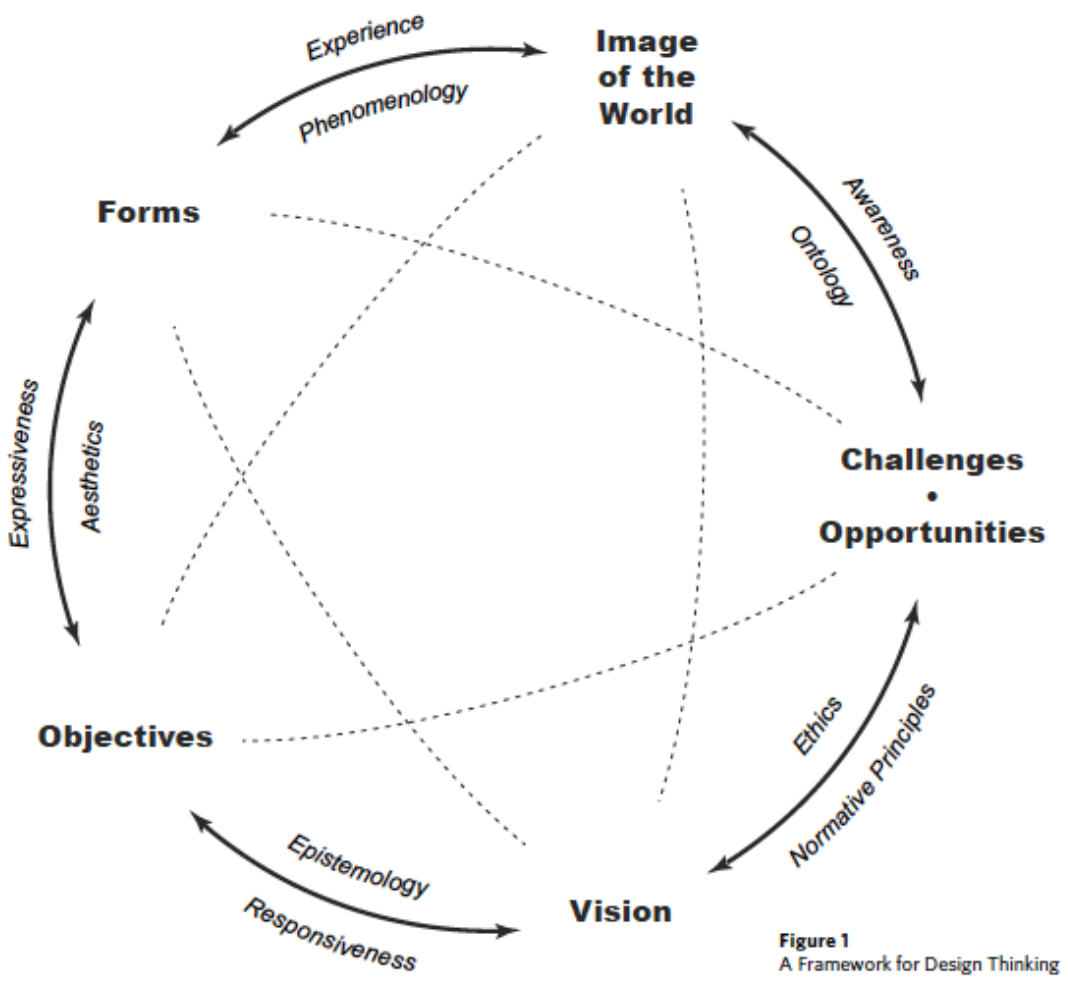


T he extensive amount of academic labor of minoritized faculty, especially at research institutions, has been well documented in the academic literature. Three tenured associate professors at The University of Texas at Austin (UT Austin) present the genesis, evolution, and postscript of leading and serving in an initiative to de-silo and encourage collaboration across the university, culminating in a collaboratively taught course. Integrating concepts of teaching in the neoliberal university context, the gendered and raced distribution of academic labor, and slow scholarship, the authors discuss the pedagogically productive process of collective teaching and decisionmaking, the frustrations inherent when employing radical pedagogy, and institutional shifts that prioritize a customerservice model of teaching, learning, and rapid research productivity. The authors conclude with reflections and recommendations for scholar-researchers similarly placed in institutional contexts where encroachments upon academic freedom and an embrace of business models collide with personal goals of career satisfaction, collective work, and improving pedagogy.

As universities become increasingly privatized, siloed, and entrepreneurial; as academic labor becomes more contingent; as public funding for universities diminishes even as costs rise; and as "success" is increasingly measured by graduates' salaries and grant funding yardsticks that call the value of the arts and humanities into question, "we could," Andrew Whelan suggests, "actively query why, given what we do know about the structural production of complex social problems, everything seems to go along just the same. What is it we don't know?" (Whelan, 2016, p. 57). Whelan further states that "teaching and research are cast in such a way as to foreclose alternative forms of pedagogy or community engagement which would make more widely known and therefore real the possibility of actually really doing things in different ways" (p. 57). What radical potential can be released when we find ourselves "actually really doing things in different ways?" And why is that radical potential so very difficult to realize?

Miranda Joseph's essay "Investing in the Cruel Entrepreneurial University" evokes Lauren Berlant's notion of "cruel optimism" (2011), and resonates with the experience that we recount here: three faculty members (all tenured associate professors, two of us white women and the other an African-American man) in three different departments (American Studies, Design, and Higher Education Leadership) at a major research university, coming together on a series of university-wide initiatives that excited us and suggested possibilities for remaking the university and creating and teaching a collaborative course on the History and Future of Higher Education. Taking advantage of a rare institutional moment when we were able to obtain funding and high-level support for an experimental course, we co-created a syllabus that would not only offer students from different backgrounds and at different educational stages a grounding in the history of higher education but also, we hoped, give them the tools and the opportunity to apply that knowledge of the past to designing possible futures that would reflect their worldview. We recount and attempt to theorize this work not just as an example of the radical possibility (and limitations) inherent in collaborative, interdisciplinary teaching, but also as an example of the ways in which excitement about "innovation" and "design thinking" - trends often associated with the neoliberal restructuring of higher education-might be harnessed by faculty and students to promote positive change in the university.

However, the timing of our effort, inextricable from forces transforming higher education in troubling ways, suggests that we were up against powers much larger than we had the capacity to take on. Indeed, during the time chronicled in this essay, or approximately six years, one president was forced to step down because he was too committed to "impractical" (i.e. not obviously monetizable) research, two major institutes in our university system devoted to innovation started and then failed, and one of us has been relocated to a new school at the center of the university's neoliberal restructuring of late. Unsurprisingly, by the most obvious yardstick this article is a chronicle of failure.

\section{But like "innovation" itself, in recent years design thinking has been co-opted to serve corporate models of higher education.}

While we learned a great deal about collaboration, genuinely bonded with one another, and leveraged institutional resources to create a dynamic and stimulating pedagogical environment, we also experienced firsthand the disincentives that come with innovation and collaborationand the struggles inherent to the project of venturing into uncharted academic waters, despite the lip service to "innovation" and "thinking outside the box" from administrators. This article is our chronicle of engaging in service and teaching in the neoliberal university context (Slaughter \& Rhoades, 2000), where much of the academic labor is relatively unrecognized, and taken on by those who naïvely want to enact positive change in their academic spaces.

\section{As Joseph (2015) notes:}

[E]ven those of us with decidedly more privileged relations to the academy in the form of relatively secure employment might be or have been understood to be working for, aiding, and abetting institutions that wear us down, and fail our desires for them and ourselves. (p. 493)

Even as we start by acknowledging our difficulties, we want to take seriously the possibility of making something from a failure, one that came and comes at a critical moment of change in our university and in higher education more generally. As members of a "Faculty Innovation Task Force," whose origins and evolution we trace below, we were charged with transforming the university: breaking down barriers between research and teaching, students and faculty, and the university and the community that it serves and in which it is enmeshed. That effort introduced some of us to the tantalizing trend toward using "design thinking," a radical collaborative process hailed in many quarters as a 
path toward positive innovation in higher education. But like "innovation" itself, in recent years design thinking has been co-opted to serve corporate models of higher education. We took our work seriously enough that when the provost created a grant competition for collaboratively taught courses, we decided to propose a class that would put our ideas into practice and take on the "wicked problems" (Rittel \& Webber, 1973) facing higher education today. We would ask students to approach higher education and the series of "challenge-opportunities" (Shearer, 2016) within this field as complex, socio-political, economic and spatial problems with stakeholders that demand interdisciplinary research, collaboration, and public negotiation to be "tamed," let alone solved. ${ }^{1}$

Just as we three faculty would need to learn to work collaboratively, so would our students: we centered the course around team projects taking on fundamental social, political, economic, cultural, technological, and intellectual issues in higher education, asking students to propose forward-looking solutions by imagining the purpose of higher education in 2025 and by self-consciously aligning themselves either with the status quo or with an alternative worldview that would necessitate a reframing of priorities.

When the three of us committed to co-teach a class combining our various disciplinary perspectives, thanks to Kate's expertise as a professor of Design, we drew upon a form of critical and speculative design (Malpass, 2013) that references Cross's (1982) "Designerly Ways of Knowing" as opposed to a neatly packaged and branded approach to "design thinking," as we discuss below. This messy process of critical and speculative design challenged and often frustrated the students, as did the inevitable logistical challenges that arose as we co-taught this new course. We focus here not just on the "cruel optimism" we brought to this work and the pushback we received, but also on its considerable rewards, from our perspective and also from the perspective of students who ultimately cited our course as transformative. The essay concludes with our reflections on the lessons learned: How we were tested and challenged to meet our own inflated expectations as well as the demands of administrators, peers, and students. How we came to recognize the costs of innovation and radical pedagogy. How we faced the uncertain terrain of mid-career scholars. And how we grew as teachers and professionals.

Berg and Seeber (2016), drawing upon Barry, Chandler and Clark (2001) and others, note that "there has been resistance to the pervasiveness of managerial power and corporate values" in higher education, often initiated by "those in middle and junior levels [who] are actively seeking to keep alive the craft of scholarship by mediating and moderating the harsher effects of the changes through supportive or transformational styles of working" (pp. 9-10). We hoped that our class could be part of that resistance, fostering the improvement of higher education through initiatives coming from students themselves, with our guidance.

\section{Genesis of Collaboration: Faculty Labor Leading to Course Development}

Late in the spring of 2014, then-Provost, now-President of The University of Texas at Austin (UT Austin), Greg Fenves, asked Julia to join "a small group of distinguished faculty members who are committed to undergraduate education... and are active and recognized researchers in their disciplines" in planning a day-long "Campus Conversation." Julia sent a hesitant reply, asking about the time commitment. It's not like the provost emails her every day, but she had been right to worry. The provost's "Faculty Working Group" (FWG), which she did join, planned not one, but two "Campus Conversations," and each of the FWG's six members also wound up chairing a task force; our class emerged from the most ambitious of those, the "Faculty Innovation Task Force," which Julia was asked to chair.

Meetings with the FWG, then-Provost Fenves, and other administrators were stimulating and inspiring: the FWG discussed the mundane business of planning "campus conversations," but also considered challenges facing the university and how faculty and students could be involved in positive change. There was an air of mission about the work, as Fenves explained that the university community needed to better articulate the "value-added benefit" provided by our public, residential research university. The term "valueadded benefit" rubbed Julia the wrong way, but she also saw Fenves's point, considering that our president at the time was under siege from the Board of Regents, who rejected his commitment to non-revenue generating research and liberal arts education. Indeed, that summer an emergency Faculty Council meeting was held to defend President Powers from what became known as the "July 4th Coup." The president was allowed to stay for the immediate future, but promised to step down in a year-allegedly, a victory for the faculty.

At the initial Campus Conversation in fall 2014, about 150 faculty discussed the future of the university and the questions that drive our research. As Julia spent the day talking to the neuroscientist, architect, musician, and historian with whom she'd been seated, she felt a tremendous sense of possibility about what could be achieved through regular conversation among diverse faculty, students, administrators, and community members.

Julia was initially thrilled to be appointed chair of the Faculty Innovation Task Force, with the charge to propose a center that would help make UT Austin "the smallest big university in the world," a daunting yet galvanizing task. Meetings of the dozen-member task force were generative and filled with utopian energy. Several of us went on site visits (e.g., to Red House at George Mason University, the Futures Initiative at CUNY, and the Gray Center for Arts and Inquiry at the University of Chicago) to actually see initiatives in action. Some went to the d.school at Stanford and learned the ways they were applying "design thinking" not just to design objects like coffee tables, but also to rethink systems and practices. 
Kate, who joined the task force when we began conceptualizing spaces for the new center, explained to us that design methods are organic processes that can be utilized to facilitate, research, co-design, and incorporate concerns and needs of various stakeholders. These processes illustrate the potential impact and costs, and most importantly, the larger worldview that any given project will support. But Kate also noted that a design approach can be used by marketers to protect vested interests and to facilitate "quick fixes" for the purpose of "selling" a concept. Thus, design thinking has both been hailed as "the new liberal arts" (Miller, 2015) and as a tool for re-establishing the university's relevance in the 21st century; but it also has been criticized by opponents of the neoliberal university.

To continue the conversations and exchange of ideas, our task force organized "Idea Lab" dinners, again, with faculty from all around the university who had expressed interest in collaborating on large-scale issues, especially those related to transforming the university itself. One dinner was held outside, in a beautiful courtyard; another was in an art gallery with a visual note taker helping us see how our ideas fit together.

We even had someone start working on a documentary film about our efforts. But like much of what we did, this yielded little fruit.

\section{Service Responsibilities and Burdens for Marginalized Faculty}

Decades ago, Exum, Menges, Watkins, and Berglund (1984) argued that women and minority faculty encountered barriers in the academic labor market, due to nature and custom that favored white men, the absence of explicit job descriptions, and formal evaluation criteria. More recently, Guarino and Borden (2017) voiced similar concerns: in an analysis of national faculty survey data, they found a gender imbalance between men and women, specifically in the area of service-controlling for organizational and cultural factors -with women bearing a disproportionate part of "taking care of the academic family" (p. 690), falling in line with a trend since the late 1990s (Antonio, Astin, \& Cress, 2000; Porter, 2007; Link, Siegel, \& Bozeman, 2007). These trends are also true for Black faculty, specifically: Konrad (1991) found that Black faculty were more likely to be engaged in professional service than their white counterparts. Allen et al (2000) also found that Black men spent more hours outside of class working with students than any other demographic, and the second highest number of mean hours in administrative and committee work, behind white women. In a context with fewer institutional resources, the service and administrative responsibilities often fall to those in the least privileged positions.

As Guarino and Borden (2017) found in their research, the administrative burden of the task force rested on the shoulders of women, akin to the phenomenon that Rich has termed "academic housekeeping" (Reddick, 2011). As Julia wrote and rewrote reports, proposals, and charters for various higher-ups on deadlines, and heard from various parties with competing ideas about what and where the "innovation center" should be, she began to feel beleaguered. Her co-chair, a grant-funded scientist, who thereby ranks higher on the academic totem pole, complained that Julia had invited too many humanists and artists onto the task force and questioned other decisions. As another woman, from a male-dominated field, Julia's cochair undoubtedly felt frustrated by the uneven power dynamics between chair and co-chair but failed to recognize the pressures Julia faced.

Julia made the case to the provost that the work being done was labor intensive, and he granted stipends to task force chairs. But Julia was unable to make the case that her co-chair should also get a stipend. There was really no diplomatic way to argue that her co-chair was doing more work than most chairs of the other task forces. Nor did it feel politic to mention that by granting each chair a month of summer salary, the provost was effectively giving more to the highest-paid faculty, without consideration of the work being done. The stipend itself represented a kind of Faustian bargain, for while the generative work of our task force was a team effort, Julia felt compelled to do the majority of writing, editing, and administrative work, while trying to finish a book and teaching a full load. The money was nice, but did not add more hours to the day. Still, much in the work was rewarding, and several faculty members told Julia that this was the first time in years they'd felt invested in UT Austin and excited about the future.

Our task force presented a plan for a centrally-located, non-hierarchical, welcoming and inspiring space that would foster collaboration among faculty, students, staff, administrators, and community members, with nodes throughout campus (Kate suggested "branded" shipping containers; Rich suggested a Winnebago that could move around campus and the city). Wherever the center was located, all titles would be left at the door: all ideas would be welcome. Our space would include not just a website functioning as a clearinghouse, but also a live "concierge" who could make connections between individuals and resources, extending various technological efforts on our campus. We would have fellowships for faculty members, and also bring in artists and other people from outside the university. We created various names for the center that would emphasize linking the university's mission, as well as the various levels of collaboration. However, we were told that "Faculty Innovation Center" was simpler and more descriptive. No one seemed to hear us when we said that "faculty innovation center" sent the wrong message: why only mention faculty if the point was to bring together the entire university community?

We also argued that the word "innovation" is often tied to monetization, business models, and a fetish for "disruption," which, as Jill Lepore (2014) and Christopher Newfield (2014) argue, contribute to the dismantling of core academic values. Julia shared Lepore's New Yorker article, "The Disruption Machine: What the Gospel of Innovation Gets Wrong," with Fenves when she was part of the FWG. Lepore demonstrates that the "disruptive innovation" craze that started in business and spread to higher education is based on faulty, or deeply-problematic, assumptions: as Newfield (2014) argues, building on Lepore's work, disruption "has produced neither social progress nor economic success as such." When applied to universities, 
disruptive innovation is especially problematic because, unlike a corporation, a university's raison d'être cannot be understood solely or even primarily in terms of bottom line, despite a shared need to balance budgets. Newfield argues that sustainable innovation can happen in universities, but only if led by faculty and students.

When Provost Fenves became President of UT Austin, members of our task force were relieved that the Board of Regents had been willing to accept a president who supported faculty research; we also felt optimistic that something would come out of our efforts. However, the "Innovation Center" was put on hold: President Fenves had many other things commanding his attention, and an interim provost, understandably, did not want to launch a major new initiative.

Still, a call for collaborative teaching proposals, supported by small grants, went out to the faculty in response to another FWG task force recommendation, and several of us on the Innovation Task Force decided to propose a course modeling the "learning community" we'd imagined: if we couldn't make university-level changes we could, perhaps, do something on a smaller scale. Julia teaches a first-year seminar on "College and Controversy" (for a selective interdisciplinary major in the College of Liberal Arts) and Rich teaches a course on the History of Higher Education, required for graduate students in the Program in Higher Education Leadership-an obvious place to initiate collaboration. Kate's decision to join in the effort challenged Julia and Rich to approach material in entirely new ways-and to be skeptical about "design thinking" as it is often practiced.

\section{Interdisciplinarity often gets touted around the university, but when the dean of the College of Fine Arts faced the prospect of having an already-overstretched faculty member commit to a project without an immediate benefit to his unit, he balked.}

In a bellwether of the roadblocks we would face, Kate had to drop out of our grant proposal because her dean wouldn't support it. Interdisciplinarity often gets touted around the university, but when the dean of the College of Fine Arts faced the prospect of having an alreadyoverstretched faculty member commit to a project without an immediate benefit to his unit, he balked. The dean had wanted Kate to teach design thinking in the School of Engineering, but she refused. Now she was paying the price for being uncooperative. Grant or no, Kate still wanted to collaborate. Happily, upon being awarded a few thousand dollars in research funds, Rich and Julia were able to redistribute the wealth to include Kate.

In hindsight we should have taken more time to develop our combined course. Like fools rushing in, and feeling urgency to prove that the task force's ideas were plausible, we proposed to teach our new course in the following spring. (We'd show everyone what could be done! We'd transform the university with our class!) Spring courses were already scheduled, but Julia managed to reschedule an undergraduate American Studies course so that it met with Rich's History of Higher Education course, and deans in the College of Education approved our unconventional class. Kate retooled her studio course, "Objects and Spaces," to focus on the university (as well as the larger design of higher education). Kate's class, a studio, met six hours a week (versus the usual three), but all the classes overlapped for two hours: thus we came up with the idea of two interlinked courses focused on the History and Future of Higher Education, one explicitly from the perspective of Design but both sharing the same syllabus and demanding collaboration from all students involved. Most notably, we would use radical design principles to disrupt the usual thinking about educational innovation-to disrupt the disrupters.

When we shared our plans for the class with the now nearly-defunct Faculty Innovation Task Force, one of our colleagues said, "You know, you're going to get terrible evaluations." We agreed without realizing how painful that would be.

Our plans became even more grandiose thanks to money that practically fell into our laps: after Julia asked the acting provost why nothing was being done with the Innovation Task Force proposal (created under a great time crunch), we were offered $\$ 25,000$ to support programming associated with our course. We understood that this was really a grant to create public programming for a center that did not exist. But the funding made it actually seem possible that we could use the class to model the kind of expansive, inclusive learning community our task force had imagined. Now we had the formidable task of linking an innovative pedagogical experiment to a preexisting structure of three existing courses-one of which centered on the history of the very institutions whose practices we were critiquing.

We did this by drawing upon work in the field of Critical University Studies (CUS), which, as editors of a Radical Teacher special issue on the topic note, "pushes us to think about how we teach and research and the ways our work is always embedded in particular social, institutional, historical, and economic contexts" (Samuels, 2017, p. 3). ${ }^{2}$ If disruptive innovation was part of the logic behind a slew of recent initiatives, including the University of Texas System's \$75 million initiative, the Institute for Transformational Learning, which closed its doors less than six years after opening, or Project 2021, which both opened and closed its doors during the period discussed here (Lederman, 2018; Ellis, 2019), as with the venture Heather Steffen (2017) describes, we were able to draw upon the university's resources to critique some of its practices.

\section{Innovative Pedagogy and Pushback}

Courses on the History of Higher Education are often the bedrock of practitioner preparation programs like the one Rich teaches in, usually drawing from the works of Lawrence 
Veysey (1970), Frederick Rudolph (1962), and more recently, John Thelin (2011) and Christopher Lucas (2006). However, graduate students in higher education programs are sometimes flummoxed when considering the impact of the Yale Report of 1828, or the Morrill Land Grant Acts on their present and future work confronting a constricting economic context in both the public and private education sectors. They ask for more applied experiences that consider issues that will challenge them as they work as advisors, admissions counselors, and policy analysts. Yet, when it came to actually doing hands-on projects that challenged them to think and work in unfamiliar ways, many were unhappy.

Kate proposed we think about the history of higher education in relation to a future that we-led by our students' initiatives-might help to create. This design mindset had an immediate impact on the course, as did securing a new, super-smart classroom, created specifically to support collaboration, in the main university library (Bawab, 2015). Kate also had the idea of dividing the class into six teams, each of which would propose an intervention to address a "wicked problem" they had identified in higher education.

The six teams focused, respectively, on society, politics, academics, technology, culture, and economics in higher education. Each team, comprised undergraduate and graduate students from all three disciplines (Higher Education Leadership, American Studies, and Design), was tasked with creating a research-based proposal that had a historical component as well as a design-based, forward thinking component-culminating with a presentation at a public symposium.

Realizing that hierarchical relationships can impede collaboration, as with our vision for an "innovation center" that would leave titles at the door, we attempted to flatten the hierarchy between students and faculty and between undergraduate and graduate students. Design students were already on first-name terms with their faculty, but American Studies and Higher Education students were initially more comfortable using "Professor" or "Doctor" prefixes. In the early stages of the semester undergraduates deferred to graduate students, and Design and American Studies students often waited for the Higher Education students (graduate students and the majority) to take the lead, as the "experts." To mitigate these tendencies, we functioned as facilitators, establishing work environments similar to those encouraged by the Harkness Conferencing table (Waks, 2015), and aimed to foster an egalitarian space for dialogue.

To initiate team and class discussions we provided a collective reading packet, with texts traditionally assigned in a history of higher education course, such as the Yale Report of 1828 and Veblen's (1918) "The Place of the University in Modern Life"; works by CUS scholars like Newfield (2011) and Frank Donaghue (2008); scholarship on student protest movements; as well as design-related articles such as Cross's (1982) "Designerly Ways of Knowing" and Dilnot's (1993) essay, "The Gift." We also had each of the Higher Education Leadership and American Studies students read a novel about college life, such as Johnson's (1912) Stover at Yale or Smiley's (1995) Moo.

Collaboration-and funding from the provost's officeallowed us to offer an unprecedented slate of speakers, including design expert Robyn Liu, who uses design thinking to assist the Australian regional government in addressing pressing social issues in local communities, engaging all constituencies while doing so; Leonard Cassuto, whose book, The Graduate School Mess (2015), has challenged both professors and administrators to more effectively prepare graduate students in the humanities for careers outside of the academy; and Christopher Newfield, whose books Unmaking the Public University (2011) and The Great Mistake (2016) have forcefully challenged the trend toward corporatization of the academy.

Indeed, Newfield's work critically informed our enterprise. In Unmaking the Public University (2011), from which our students read excerpts, Newfield emphasizes the essential link between public research universities and what had long been "a mainstream and politically powerful ideal" of what it means to be "middle class": this ideal assumed
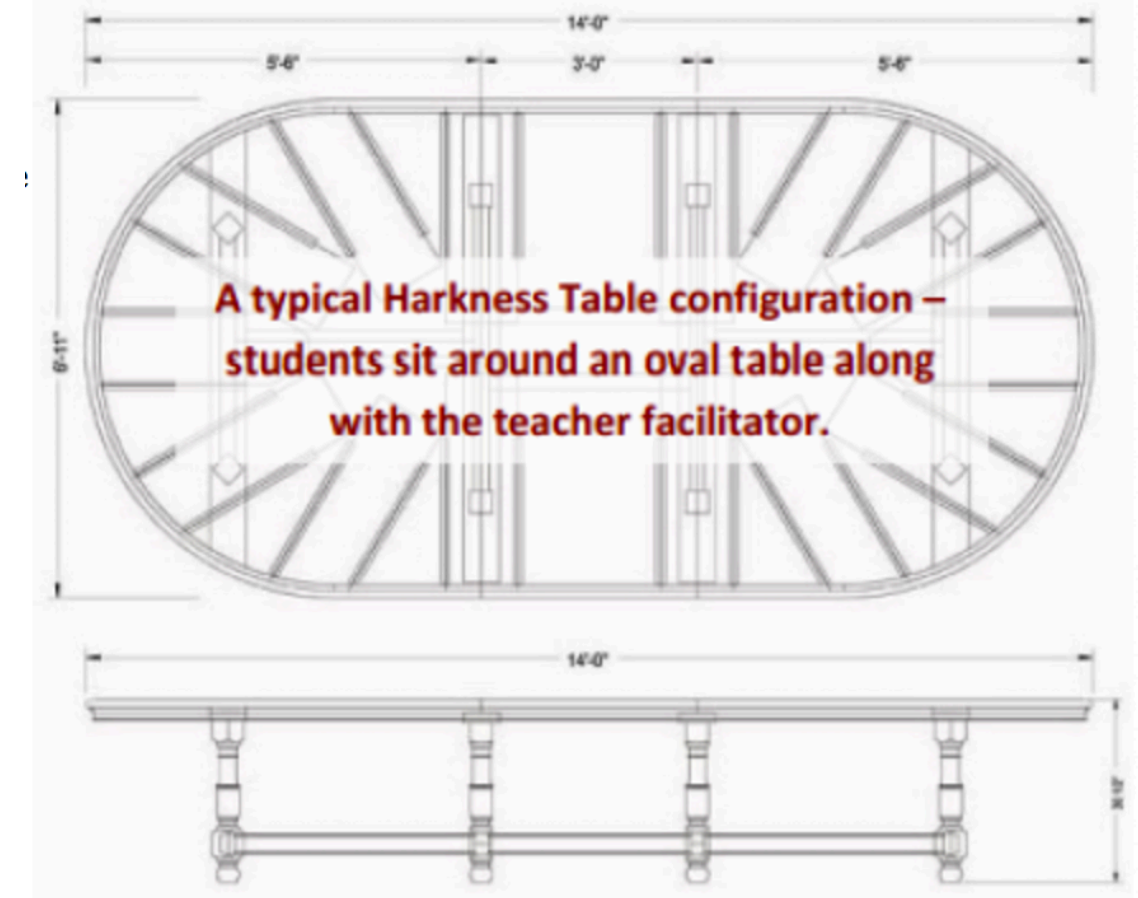

FIGURE 1. DIAGRAM OF THE ORIGINAL HARKNESS TABLE (D. R. DIMES \& COMPANY, LTD., 2018; TRUSTEES OF PHILLIPS EXETER ACADEMY, 2018).

that the "majority was to have interesting work, economic security and the ability to lead satisfying and insightful lives, in which personal and collective development advanced side by side" (2011, p. 3). However, as Newfield notes, if a core principle underlying the broad social egalitarianism of research universities was that "educational needs should dictate budgets and not the other way around" (2011, p. 2), 
by the 1970 s that principle was under fire, as states began disinvesting in public universities and as universities thus became increasingly privatized, reliant on corporate partnerships, and concerned about balancing budgets. Newfield's work encouraged us to think about the university's relationship to the larger society, and his insistence that innovation initiatives come from faculty and students, rather than from administrators (or "managers") informed the work we asked student teams to perform.

We also brought in others from the university and the wider community (e.g., administrators and former campus activists) as guest speakers, discussants, and tour guides: students got both an architectural tour and a racial geography tour of the UT Austin campus and also visited a local historically Black university. Our class was open to visitors (e.g., faculty and staff colleagues, students who were not enrolled, and members of the community), who prepared for class as our students did, and joined our conversations. In addition to organizing a day-long symposium in which students shared their proposals with stakeholders and interested parties in the university and in the wider community, we created a small grant competition that would allow a team of students to launch their proposed project.

Presenting students with unfamiliar problem-solving strategies and intellectual frameworks initially was a point of contention for all: This was particularly the case for graduate students in Higher Education Leadership, who were being asked to question the logic of the very roles they were being trained to assume. Some of the American Studies and Higher Education Leadership students couldn't understand why they were using critical and speculative design strategies, and many of the Design students were uncomfortable "teaching" their peers. They had difficulty articulating what they do, how they do it, and why they do it, and did not at first understand that they would gain skills as designers by having to collaborate with students from these other fields. Eventually (and this took longer than we'd assumed it would) something clicked, and suddenly the American Studies and Higher Education students began requesting more time to talk to the Design students and those students began to recognize the utility of thinking through design processes with peers who were versed in cultural, historical, and social frameworks that they might lack.

The frustration our students experienced was almost certainly a manifestation of the siloing inherent in the contemporary university: students are conditioned to specialize and to frame issues from one disciplinary lens, so an interdisciplinary approach was foreign, unfamiliar, and "wrong" (less of a problem for students in American Studies, interdisciplinary at its core, but as undergraduates, they tended to follow the lead of the Higher Education graduate students). In essence, we had to patiently help our students make sense of unfamiliar concepts, embrace a sense of ambiguity, and then learn from each other in a collaborative, nonhierarchical space. Unfortunately, many of the students came to really appreciate this challenging and timeconsuming process only after they'd filled out course evaluations.

\section{Designing the History and Future of Higher Education}

Design students brought to the course visualization and modeling skills and a way of thinking expansively about the course topic using a collaborative and generative design approach to structure the development of arguments for change. But if the expectation was that Kate and her students could bring "design thinking" methods to a consideration of higher education's history and future, she was eager to complicate that expectation. Recent articles have touted the promise of "design thinking" for higher education (Gardner, 2017; Lorenzo, 2016), but the approach espoused by firms like IDEO and institutionalized in Stanford's d.school-often boiled down to five "modes" ("Empathize," "Define," "Ideate," "Prototype," and "Test") and signified by creative types using white boards and PostIt notes-has its limits. Noting her concern about the promotion of design thinking to "disruptive agent" in higher education, designer Amy Collier (2017) points to "how easily people move from design thinking having a helpful role in students' learning to 'solving' higher education's greatest problems that, frankly, may be too complex for design thinking."

Design thinking as appropriated
by business schools, and as
increasingly applied to the larger
project of "innovation" in higher
education, typically does not
critically assess the worldview
within which a new product, city,
transportation system or course
exists.

Design thinking as appropriated by business schools, and as increasingly applied to the larger project of "innovation" in higher education, typically does not critically assess the worldview within which a new product, city, transportation system or course exists. Kate encouraged students to approach the topic of higher education's future as a systems-level issue and an inherently "wicked problem." To structure this unwieldy topic, student teams referenced a text by Allan Shearer (2015) outlining a history of design methods and borrowed his flexible Design Thinking Framework. Design students guided their teams' use of the framework both to structure initial negotiations and to develop the narrative backbone of presentations. Using Shearer's design thinking framework nudged students into an open dialogue, exposed assumptions, uncovered disciplinary predilections, and forced teams to explore a tendency to accept dominant ideologies as a given.

Acknowledging that personal experiences can shape values and sometimes invisibly determine priorities that shape research agendas we began by asking each individual to reflect on and share the story of their personal journey to higher education. Self-awareness when entering into a collaboration is essential. We then asked student teams to either consciously align themselves with the status quo, or 
to explore an alternate worldview that would necessitate a re-framing of priorities in answer to the question: "What will be the purpose of higher education in 2025 (or later)?"

We guided research and concept development gently, using smaller assignments (cognitive mapping exercises, adopting Shearer's design cycle), and constructing scenarios that included a target (place), a time period (no sooner than 2025), a character from relevant constituencies (student, faculty member, parent of student, staff member, alum, etc.), and the kind of interaction or experience being addressed (admissions, distance learning, student debt, etc.). We used speed critiques, where the teams made quick pitches, both visual and verbal, and the group and faculty gave feedback. Through this process, we sensed that most participants felt engaged and vital to the success of their team's project by mid-semester. We were thrilled as students increasingly shared expertise and began to meet outside of class regularly. As student teams began to work more autonomously, they acquired a real sense of agency and ownership of the process. As a result, they did not need to defer to faculty as frequently.

In the 2011 ICOGRADA Design Education Manifesto, designer and educator Meredith Davis argued that common design education practices that offer individual students simple or already "tamed" problems to solve, problems situated in artificially stable contexts, does them a great disservice. Like Davis (2011), we felt that students in our programs were shielded from the complex challenges of their time and that graduates were often ill-equipped to engage with others in addressing such systems-level problems. As they negotiated higher education as a "wicked problem," student teams met with policy makers, university administrators, politicians, and professional designers, and were challenged to address the multifarious needs of these diverse stakeholders, whose conflicting priorities made consensus and clear problem definition impossible.

Ultimately, the team members became somewhat more comfortable initiating plans for change in imperfect circumstances. They established a few initial parameters in order to start moving towards a resolution by deadline. They proceeded, at first cautiously, through rapid cycles of research, discussion, and propositions, all the while arguing, testing, and redesigning. Some were distressed that the research was on-going throughout the process, not completed in advance, but these conditions replicated many real-world situations. They tweaked parameters and eventually honed goals using the abductive methods inherent to the iterative design process and methods that would eventually, if somewhat painfully, lead to relevant conclusions and the development of proposals addressing issues like course evaluations, financial aid, student activism, university communications, and open educational resources. Finally, the teams had to accept the reality that once framed, the relevance and appropriateness of their proposals would evolve and change over time (Rith \& Doubberly, 2006), necessitating continual tweaks or fundamental redesigns in the future.

When economist Herbert Simon (1996) stated, "Everyone designs who devises courses of action aimed at

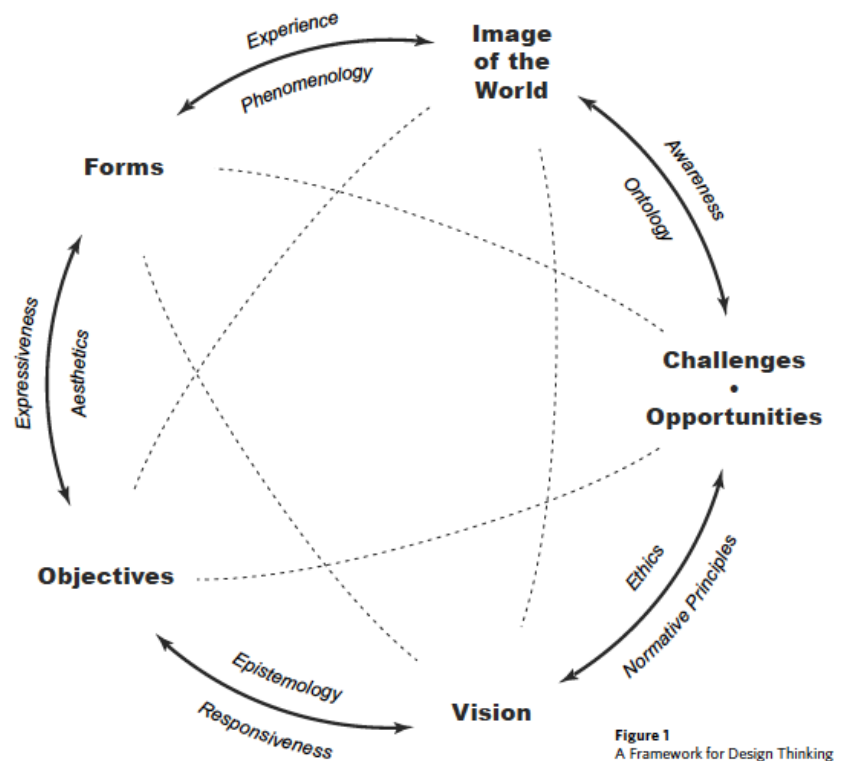

FIGURE 2. SHEARER'S (2015) DESIGN THINKING FRAMEWORK, FROM ABDUCTION TO ARGUMENT: A DESIGN THINKING FRAMEWORK.

changing existing situations into preferred ones" (p. 111), he recognized that design itself does not have a subject; it is a process that can be applied to any subject area to identify priorities and to propose possible futures. Simon acknowledged the utopian aspirations of the designer and delineated the iterative process that informs debates along the way, leading to the framing of an argument for doing things differently in the future. Our student teams grappled with this definition of the designer throughout the course, but ultimately understood, through doing, that design could frame arguments for change in relation to any given topic. They also embraced the opportunity to use their unique personal and disciplinary perspectives to shape meaningful change in higher education.

The teams ultimately succeeded in proposing a range of relevant interventions for higher education, recognizing that neither the process, nor the outcome, was perfect, but that their proposals could positively affect conversations about the trajectory of higher education for the next generation. Chris Newfield joined forces with Beto Lopez (formerly of IDEO and now head of UT's Design Institute for Health) to respond to the students' initial iterations of their proposals, and both were impressed, by the process even more than by the products: as Newfield said of the students, afterwards in conversation, "they're committed to a meaningful version of the university and they're thinking very concretely about how to get that."

\section{Design, Politics, and the Neoliberal University}

Design as a field has increasingly been at the forefront of efforts to turn public research universities into vocational training schools. There is a rather uncritical euphoria surrounding programs-such as one recently created in our university (which employs almost entirely non-tenure-track 

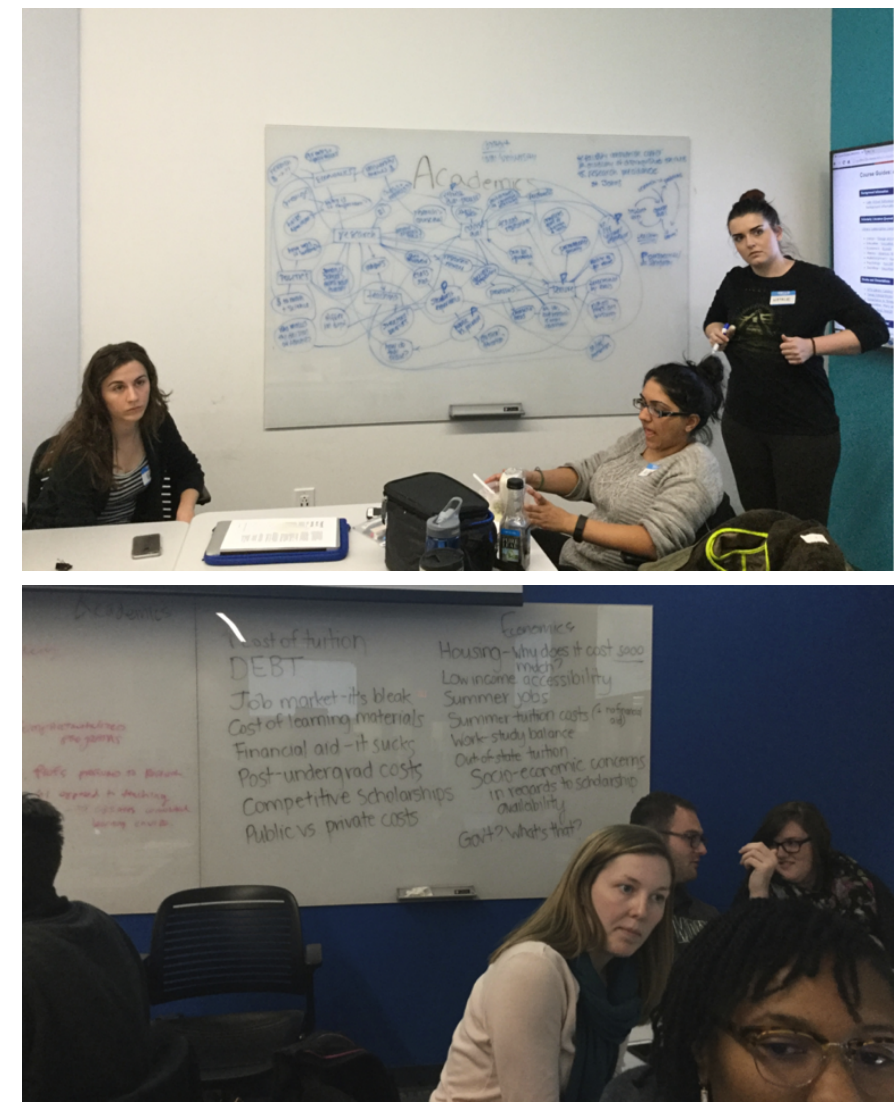

FIGURE 3. TEAMS USING THE CONFERENCE METHOD (AND A DESIGN-BASED MAPPING STRATEGY) IN NEW CLASSROOMS WE WERE ABLE TO RESERVE IN THE UNIVERSITY LIBRARIES FOR OUR COLLECTIVE COURSE.

faculty)-that will soon permit off-site, internship-heavy, and otherwise commercially-oriented research. These initiatives yield economic benefits for the University, employment opportunities for some students, and funding for certain areas of faculty research. However, they also have the potential to replace alternate, less economically persuasive design research pathways. This leaves more experimental and less obviously lucrative research to private institutions, undercutting the historically democratic mission of public universities.

Newfield (2016) has suggested that the R1 university, whose engineering programs have long been the cheap R\&D workshop for the U.S. government, is fast fulfilling a similar role for private corporations. In this iteration of the public university, students, rather than being reimbursed at a rate commensurate with industry-based internships, are paying tuition while serving as cheap intellectual laborers in the service of big business.

State political leaders have taken aim at the UT Austin, ousting one president and de-vesting the institution, providing only $12 \%$ of the university's budget today (in $1984,48 \%$ of the budget came from legislative appropriations). Many of these same politicians have the audacity to publicly question the science behind climate change and to advocate on behalf of the gun lobby (students are now allowed to carry concealed weapons to their classes). In addition to creating a range of unfunded mandates, the legislature's actions contribute to a culture of fear and confusion that in turn limits critical discourse and academic freedoms within the university. In this environment teaching students to make arguments for futures that embrace sustainability, that question the very idea of "human centered design," run contrary to the mainstream and may even seem radical. In this world, design easily becomes political (Rittel \& Webber, 1973).

\section{Reflecting on Collaboration and Interdisciplinary Inquiry}

This current state of affairs in higher education speaks to the final intervention that the course made: our effort to reimagine the process of college instruction. As a graduate student, Rich read Paulo Freire's work and was fascinated by his description of "banking" education, described in Pedagogy of the Oppressed (1970):

Instead of communicating, the teacher issues communiques and makes deposits which the students patiently receive, memorize, and repeat... [T] he scope of action allowed to students extends only as far as receiving, filing, and storing the deposits. (p. 58)

A similar mode is the transmission model, where there is "a fixed body of already existing knowledge that needs to be taught and learned. Teaching essentially consists of the transmission of the body from the teacher to the pupil" (Nola \& Irzik, 2005, p. 175).

However, in a liberatory pedagogy, Freire argues, education comes through dialogics, utilizing cultural knowledge and cooperation to address social problems. Instead of primarily focusing their attention upon learning a body of information that the professors taught, the six topical groups had the opportunity to research, integrate, and synthesize knowledge, and to propose their own, original approaches, or interventions, with which to address a range of problems (or, drawing from Shearer [2015], what we took to calling "challenge-opportunities") now confronting higher education.

In reality, problem-addressing, and problem solving, rarely happen in an off-the-shelf manner. Our effort to move from banking and transmission to liberatory approacheswith all the challenges of teaching an inaugural first-of-itskind course-was itself a challenge-opportunity. As was the effort to collaborate on a deep level with colleagues with different modes of training, epistemological perspectives, and disciplinary norms. We did not accurately anticipate how difficult and time-consuming it would be to alter course protocols at UT Austin, to negotiate ingrained teacherly habits, to collaborate across disciplines, and to test out new methods, while keeping all participants on board. We observed that many of our students became frustrated when they couldn't get an immediate response to questions posed over email: a consumer-driven model of the university amps up student expectations about email response times from professors, a reality made especially challenging by our need to coordinate responses. When teamwork progressed smoothly, class meetings were relaxed and productive, but when a team lacked direction, a deadline loomed, or worries about collaborative grading became too much, anxieties sometimes led students to panic and direct backlash at faculty, the teaching assistant, and, on occasion, peers. 
Certainly, we as faculty members made mistakes: our biggest mistake was trying to fit too much in without recognizing how much time effective collaboration really takes, for students-and us as well: in addition to the major projects we had each of the Higher Education and American Studies students do an ethnography and also had them read and report on a college novel, i.e. "the imagined university," while Design students were asked to do critical analyses of teaching spaces on campus. We should have done less. But we wonder now how much our identities (two white women and an African American man) impacted the pushback we received from students, who were unused to having authority decentered in the classroom, and wanted to know exactly what they needed to do to be successful in the course.

As the day-long symposium approached, at which team proposals would be pitched to a public audience, stress levels soared. However, on the day itself, the euphoria and sense of achievement was palpable as student teams rallied to present cohesive proposals that were well researched and well-argued, both visually and verbally. Unfortunately, we had to administer course evaluations at the meeting prior to the symposium, seeking feedback at a moment when students felt most vulnerable. Thus, the primary metric used to evaluate our course's "success" is arguably skewed (Estelami, 2015).

Despite the unfamiliar terrain and some inevitable course pacing issues, we received many positive responses from students after the course's end, even from those expressing the highest levels of confusion and frustration during the semester. They wanted us to know that their experiences in the course had positively, almost immediately, influenced their educational or professional goals. One student told us that she used the design thinking methodology during a summer internship in Washington, DC, which impressed her supervisors. Another mentioned that comfort with ambiguity she developed during the course had been a great preparation for doctoral studies.

In final reflective comments (turned in after official evaluations were done) students observed how difficult it is to make even small changes in the university. One Design student asked, "Why is it when the university wants change to happen and wants to start that which 'changes the world,' we can't even make a course to combine different majors without fighting the university to do so?" A graduate student in Higher Education mused on the indicators of a good education, going beyond the current obsession with immediate job placements: "... if a student leaves college having a better understanding of who they are as a person, a clearer moral compass, and motivation for their path forward, well, isn't that success?"

Three years on, we continue to apply much of what we learned in teaching this unique course. As faculty in different departments, we still look to each other for feedback and support, and we each seek out initiatives that breach the conventional formats of our classrooms, such as active learning strategies recently acquired from colleagues in the theater department. But we've also seen the critiques of the neoliberal university that we taught in our class resonating with changes at our university, some of which have made it harder to carve out time even to co-write this article, especially as it is unclear whether it will "count" toward promotion for some of us.

\section{Course Post-Script}

With our course, we made an argument for breaking silos, for creating non-hierarchical learning spaces with instructors who guide rather than lead, for students to coconstruct their educational experiences, and for teams to build knowledge collaboratively while devising solutionsfocused proposals. A digital Scalar "book," created by students, now serves as a record of the course, providing access to lectures, readings and assignments, keeping that work alive and accessible to the public (Barba, Campbell, Wilson, \& Zaldivar, 2016).

Part of understanding this teaching experience is recognizing how time-intensive collaborative coursebuilding can be, the impact such pedagogical experiments can have on careers, and the potential for less stable student evaluations. If the risk-laden process of experimentation and development of innovative courses is to be supported at public universities, participants need to be protected from the negative consequences of experimental practice-not just negative in terms of students' resistance, but negative in terms of the time required to do this work. We obtained grants, but teaching this course took away from time to do work that earns us promotions and raises. There is a lot of talk about encouraging experimentation and innovation (and even collaboration) but in the grand scheme of things, small, one-time grants count for much less than time and longterm merit raises. These consequences are especially weighty for scholars without the protection of tenure, or the security of full-time employment.

Even for tenured, full-time faculty, especially those with marginalized identities, there are risks. Research shows that gender bias can negatively impact women's course evaluations (MacNeil, Driscoll, \& Hunt, 2015), and Black academics are held to a "performance" standard in academic spaces, rather than one based on the content of their work (McGee \& Kazembe, 2015). However, as our colleagues on the Innovation Task Force had warned us, we should have expected negative evaluations, given that we took a considerable risk in disrupting course structures, pedagogy, and products.

Gardner (2017), reflecting on his experience at Stanford's d.school, noted, "To do design thinking properly, we would need to embrace failure, even celebrate it, because trying and failing and trying again is key to the process." During Julia's recent promotion to full professor, the only question about her teaching was why evaluations in this one class were so low. This "failure" was not celebrated at the moment it counted.

Equally important to both faculty buy-in and effective course development is the design and introduction of flexible, long-term evaluation methods. Without such support, low course evaluation numbers have immediate and negative consequences on opportunities for promotion and merit increases. 
In a seminar Rich attended recently, Harvard Kennedy School professor Dana Born discussed the paradox of the espoused value of risk-taking in organizations, compared to the actual cultural rewards (and punishments) in those same organizations. Many of us present agreed that we had heard strong rhetoric at the Campus Conversations and elsewhere about the merit of risk-taking, but we've also seen that "failures" result in firings, demotions, or even the stigma of championing a lost cause. Virgin CEO Richard Branson's borrowed quote from playwright Samuel Beckett, "Ever tried. Ever failed. No matter. Try again. Fail again. Fail better" (as quoted in O'Connell, 2014) does not acknowledge the penalties inherent in risk-taking. Indeed, we have collectively imagined what it would be like to "fail better" by teaching the course again, with the benefit of our previous experience to augment those aspects that didn't work as well as we'd hoped. Very quickly, the disincentives (as much as we would enjoy it, and as much as we believe it would be a benefit to our students) re-emerge and we change the topic. One day in the future, perhaps?

We have not yet succeeded in changing the culture of teaching and research at UT Austin. While the university has created a new Faculty Innovation Center (FIC), it has a different focus and staffing structure than the Task Force imagined, and is essentially a rebranded Center for Teaching and Learning. The difference between the FIC's current configuration and the dialogue that initially inspired it could prompt cynicism, and it has. Still, the leaders of the FIC, which came into being around the same time we were teaching our class, were, and remain strong supporters of the work we (and our students) were doing, and invited us to get involved with the center.

In becoming president, former provost Greg Fenves had successfully leveraged the Campus Conversations, the task forces, and the faculty engagement he'd helped to promote. But after Fenves left the provost's office, such initiatives ended. After a new provost was hired, Julia requested an appointment with her to discuss the Faculty Innovation Task Force's proposal, but after multiple reschedulings Julia was finally told there was no room on the provost's calendar, and there would not be any room in the foreseeable future. This was disheartening, but it was a small victory to discover that Fenves, learning that we were bringing Christopher Newfield to campus, invited this trenchant critic of higher education administration to discuss the challenges facing public research universities.

As we write, a university program created to leverage the skills that the humanities can bring to business has teamed up with the School of Design and Creative Technologies to offer a new series of three-day design thinking workshops, charging $\$ 1,800-2,500$ per seat (Human Dimensions of Organizations and School of Design and Creative Technologies, 2019). These creative thinkingto-action courses are aimed at both corporate audiences and educators. Workshop promotional materials suggest that after completing a three-day course attendees will be fully equipped to put their "ideas into action." Such grandiose promises of design-driven transformations seriously understate the complex problem-spaces that our students negotiated within the space of higher education, and the instant-expert certificate stands in stark contrast to the nuanced, messy and necessarily slow acquisition of knowledge so central to a high-quality university education. Lucrative workshops help support public education at a time of diminished public funding, but they also threaten to damage the ethos, research and educational mission of the university.

\section{Implications and Reflections: Taking Risks, Embracing Slow Scholarship}

Rather than end on a skeptical note, we'd like to invite speculation about how our experience might point toward the possibility of faculty-driven institutional change, where that change might come from, and where it might lead. Although we don't know how much if any credit we can take for it, many of the ideas proposed by the Faculty Innovation Task Force have been absorbed into a range of ongoing projects at UT Austin, from Pop-Up Institutes to the even more ambitious Bridging Barriers Program. Faculty and students involved in these initiatives (including each of us) have reflected favorably on their interaction with scholars and researchers from varied backgrounds.

Reflecting back on the experience of serving on the task force, and on the course we created, we acknowledge that we operate from positions of privilege: we are all tenured at a well-resourced institution, and had grant support for the course and related programming. Many of our colleagues who lead, or might want to lead, these sorts of collaborations may not have these advantages. In fact, we would strongly urge scholars in more precarious academic positions (assistant professors, adjunct and non-tenure-track faculty, as well as graduate student instructors) to think carefully before embarking on wide-reaching projects such as ours. Although our teaching evaluations took a one-time hit, we have strong teaching records and could "afford" the risk of innovating with our pedagogy and approach.

Our collective work and subsequent reflection made clear to us the ways that our individual voices, and those that intellectually and personally sustain us, can be muted in the academy. Fortunately, we found powerful allies who advocated for us in spaces to which we did not previously have access. We also recognized the importance of finding ways to translate our teaching passion into academic capital: we forged connections with CUS scholars Christopher Newfield and Marc Bousquet, presenting together at a session of the American Studies Association's annual meeting (Catterall, Mickenberg, \& Reddick, 2016). And this collaboratively authored article is a scholarly publication that may "count" in ways that our course did not (though it may not be weighted equally in our respective disciplines).

Our recommendation for those seeking to de-silo their academic lives is to think about how the process itself might be leveraged for the currency needed for tenure, promotion, and recognition, even as we'd confirm that the best reason to collaboratively teach across disciplines is that it makes us grow as thinkers, teachers, scholars, and people. It is a sad reality that the push for greater faculty productivity leads us to consider our teaching in relation to quantifiable metrics of "productivity" (Slaughter \& Rhoades, 2000). On the other 
hand, the pleasures of the work itself were resistance to the emphasis on academic throughput and output, as Berg and Seeber describe in The Slow Professor: Challenging the Culture of Speed in the Academy (2016). We like sitting down together and talking about this stuff.

One of our guest speakers, Leonard Cassuto, told the class that our collective endeavor was "brave." While we are more modest regarding this label, we agree that collaboration and de-siloing the academy in the current political climate in our state and nation is a risky proposition. With an increasing focus on metrics and outcomes rather than process, we took on a project that resembled what Mountz and colleagues (2015) term slow scholarship:

Good scholarship requires time: time to think, write, read, research, analyze, edit, and collaborate. High quality instruction and service also require time: time to engage, innovate, experiment, organize, evaluate, and inspire. This kind of slow work both defies and is threatened by the myriad demands on our time as academic laborers. ( $p$. 1237)

The process of collaborating across disciplinary divides, within a bureaucracy that is often indifferent, and at worst, actively hostile to collaboration; learning to teach as a team; and ultimately, the process of reflecting on our experiences has taken considerable time-time that tenure and concurrent projects that we can be confident will "count," afford us. It is imperative to consider how difficult this would be if we did not have those protections. Nevertheless, we remain committed to pedagogical collaboration, and to each other as colleagues. As underrepresented voices in academia during a time Newfield (2016) refers to as "pseudointegration," we are doing our best to resist the encroachment on academic freedom that comes with the trend toward hiring untenured lecturers and "professors of practice", and emphasis on business models. One way we have done and continue to do this is by providing challenging, thought-provoking, and by-design inefficient spaces of engagement.

What was significant about our endeavor? We attempted to use a radical form of design thinking to critique or disrupt the idea of disruptive innovation in higher education. We taught students a more nuanced form of critical and strategic design methods, methods that can be used to streamline productivity or to re-conceptualize everything, starting with a political system that might sustain alternate agendas. We alerted students not just to the possibilities of design thinking but also to its limitations, suggesting that wicked problems can only be tackled effectively through a deep understanding of history and social contexts. We insisted on making our classroom and our work public, and inspired our president to meet with a prominent critic of disruptive innovation and the defunding of public universities. We put undergraduate and graduate students in conversation not just with each other but also with outstanding scholars from other institutions, administrators, politicians, faculty, and the local community, and we convinced those students that they had important things to say and learn. We asked students to imagine a future in which changes in the university would originate from the bottom up instead of the top down. We engaged with, and questioned, our own assumptions about the current state and future of the university, as instructors, as intellectuals, and as colleagues from different disciplines-in class, on a local radio program and podcast (Dryer, 2016), at national conferences, and here in this article.

Did we succeed? Arguably, by the only metric that counts in teaching, we failed. But here we are, suggesting to others that maybe we as teachers can begin to design ways to disrupt the disrupters, and redefine the terms of the debate.

\section{Notes}

${ }^{1}$ Vitasek (2014), drawing on Rittel and Webber (1973), as well as Churchman's elaboration on their work (1967), describes the core characteristics of "wicked problems" as follows:

- Wicked problems have no definitive formulation, and every wicked problem is a symptom of another problem.

- Every wicked problem is unique, and there is always more than one explanation for a wicked problem, with the appropriateness of the explanation depending greatly on the perspectives and values of those involved.

- Solutions to wicked problems are only good or bad, not true or false. The solution is largely a matter of judgement.

- There is no surefire template to follow when tackling a wicked problem; plus, solutions to wicked problems can generate unexpected consequences over time, making it difficult to measure their effectiveness.

Those attempting to address a wicked problem must be fully responsible for their actions.

${ }^{2}$ American Studies scholars have, in recent years, engaged CUS to suggest ways in which higher education reveals fundamental tensions and struggles in American society. See, for instance, Marez (2014), which originated as the 2013 Presidential Address to the American Studies Association, and the symposium in the December 2012 issue of American Quarterly (see Greyser and Weiss [2012]).

\section{References}

Allen, W. R., Epps, E. G., Guillory, E. A., Suh, S. A., \& Bonous-Hammarth, M. (2000). The Black academic: Faculty status among African Americans in U.S. higher education. Journal of Negro Education, 69, 112-127.

Antonio, A. L., Astin, H. S., \& Cress, C. M. (2000). Community service in higher education. The Review of Higher Education, 23(4), 373-397

Barba, B., Campbell, N., Wilson, J. C., \& Zaldivar, D. (2016). The history and future of higher education: A multi- 
disciplinary investigation. Retrieved from: http://scalar.ctl.utexas.edu/future-of-higher-ed/index

Barry, J, Chandler, J., \& Clark, H. (2001) Between the ivory tower and the academic assembly line. Journal of Management Studies, 38(1), 87-101.

Banowsky, B. (Producer), \& Mims, S. (Director). (2016). Starving the beast [Motion picture]. United States: Violet Crown Films.

Bawab, N. (2015, August 26). PCL Learning Commons to offer increased resources to students. The Daily Texan. Retrieved from: http://www.dailytexanonline.com/2015/08/26/pcllearning-commons-to-offer-increased-resources-tostudents

Berg, M. \& Seeber, B. K. (2016). The slow professor: confronting the culture of speed in the academy. Toronto, ON: University of Toronto Press.

Berlant, L. (2011). Cruel optimism. Durham, NC: Duke University Press.

Cassuto, L. (2015). The graduate school mess: What caused it and how we can fix it. Cambridge, MA: Harvard University Press.

Catterall, K., Mickenberg, J. L., \& Reddick, R. J. (2016, November). The history and future of higher education: A collaborative pedagogical experiment. Paper presented at the 2016 Annual Meeting of the American Studies Association (ASA), Denver, CO.

Churchman, C. W. (1967). Guest editorial: Wicked problems. Management Science, 4(14), 141-142.

Collier, A. (2017, April 17). Surprising insights, outliers, and privilege in design thinking. Digital Learning at Middlebury. Retrieved from: https://bit.ly/2HKZ67Y

Cross, N. (1982, October). Designerly ways of knowing. Design Studies, 3(4), 221-227.

design thinking workshop (2019). Retrieved from https://hdo.utexas.edu/design-thinking/

Donaghue, F. (2008). The last professors: The corporate university and the fate of the humanities. New York: Fordham University Press.

D. R. Dimes \& Company, Ltd. (2018). Harkness tables. Retrieved from: http://www.harknesstables.com/productcatalog/harkness-tables

Dilnot, C. (1993). The gift. Design Issues, 9(2), 51-63.

Doubberly, H. \& Rith, C. (2006). Why Horst W. J. Rittel matters. Design Issues, 23(1), 72-91. doi: 10.1162/desi.2007.23.1.72

Dryer, T. (2016, March 31). The future of higher education [Audio podcast]. Retrieved from: https://bit.ly/2YiqyjA

Ellis, L. (2019, March 6). Project 2021 flopped. readers took these three lessons from the saga. Chronicle of Higher Education.

Retrieved

from:
https://www.chronicle.com/article/Project-2021Flopped-Readers/245827

Estalami, H. (2015). The effects of survey timing on student evaluation of teaching measures obtained using online surveys. Journal of Marketing Education, 37(1), 54-64.

Exum, W. H., Menges, R. J., Watkins, B., \& Berglund, P. (1984). Making it at the top: Women and minority faculty in the academic labor market. American Behavioral Scientist, 27(3), 301-324.

Freire, P. (1970). Pedagogy of the oppressed (trans. Myra Bergman Ramos). New York: Continuum.

Gardner, L. (2017). Can design thinking redesign higher ed? Chronicle of Higher Education, 64(3). Retrieved from: https://www.chronicle.com/article/Can-DesignThinking-Redesign/241126

Greyser, N. \& Weiss, M. Introduction: Left intellectuals and the neoliberal academy. Americann Quarterly 64(4), 787-793.

Guarino, C. M., \& Borden, V. M. (2017). Faculty service loads and gender: Are women taking care of the academic family? Research in Higher Education, 58(6), 672-694.

Human Dimensions of Organizations and School of Design and Creative Technologies. (2019). The University of Texas at Austin design thinking workshop: More than a design thinking bootcamp. Retrieved from: https://hdo.utexas.edu/design-thinking/

ICOGRADA Education Manifesto, 2011. Retrieved from: http://www.ico-

d.org/database/files/library/IcogradaEducationManifest o_2011.pdf

Johnson, O. (1912). Stover at Yale. New York: Grossett \& Dunlap.

Joseph, M. (2015). Investing in the cruel entrepreneurial university. South Atlantic Quarterly, 114(3), 491-511.

Konrad, A.M. (1991). Faculty productivity and demographics. Thought and Action, 7(2), 19-54

Lederman, D. (2018, February 21). Lessons learned from a $\$ 75$ million failed experiment. Inside Higher Ed. Retrieved from:

https://www.insidehighered.com/digitallearning/article/2018/02/21/lessons-learnedshuttering-universitys-internal-digital-learning.

Lepore, J. (2014, June 23). The disruption machine: What the gospel of innovation gets wrong. The New Yorker. Retrieved from: https://www.newyorker.com/magazine/2014/06/23/th e-disruption-machine?reload=true.

Link, A. N., Siegel, D. S., \& Bozeman, B. (2007). An empirical analysis of the propensity of academics to engage in informal university technology transfer. Industrial and Corporate Change, 16(4), 641-655.

Lorenzo, D. (2016, December 7). Why higher education needs design thinking. Fast Company. Retrieved from: 
https://www.fastcompany.com/3066293/why-highereducation-needs-design-thinking-right-now

Lucas, C. J. (2006). American higher education: A history. New York: Palgrave Macmillan.

Marez, Curtis (2014). Seeing red: The university and student debt. American Quarterly 66(2), 261-281.

Malpass, M. (2013). Between wit and reason: Defining associative, speculative, and critical design in practice. Design and Culture, 5(3), 333-356. doi: $\underline{10.2752 / 175470813 \times 13705953612200}$

McGee, E. O. \& Kazembe, L. (2015). Entertainers or education researchers? The challenges associated with presenting while black. Race, Ethnicity, and Education, 1-25. DOI: 10.1080/13613324.2015.1069263

Miller, P. N. (2015, March 26). Is design thinking the new liberal arts? The Chronicle Review. Retrieved from: https://www.chronicle.com/article/Is-Design-Thinkingthe-New/228779

MacNeil, L., Driscoll, A., \& Hunt, A. N. (2015). What's in a name: Exposing gender bias in student ratings of teaching. Innovative Higher Education, 40(4), 291-303.

Mountz, A., Bonds, A., Mansfield, B., Loyd, J., Hyndman, J., Walton-Roberts, M., ... \& Curran, W. (2015). For slow scholarship: A feminist politics of resistance through collective action in the neoliberal university. ACME: An International Journal for Critical Geographies, 14(4), 1235-1259.

Newfield, C. (2011). Unmaking the public university: The forty-year assault on the middle class. Cambridge, MA: Harvard University Press.

Newfield, C. (2014). "Christensen's disruptive innovation after the Lepore critique," Remaking the University (blog) http://utotherescue.blogspot.com/2014/06/christense ns-disruptive-innovation.html Accessed, 15 August, 2018.

Newfield, C. (2016). The great mistake: How we wrecked public universities and how we can fix them. Baltimore: Johns Hopkins University Press.

Nola, R., \& Irzik, G. (2006). Philosophy, science, education and culture. Dordrecht, NL: Springer Science \& Business Media.

O'Connell, M. (2014, January 29). The stunning success of "fail better": How Samuel Beckett became Silicon Valley's life coach. Slate. Retrieved from: https://bit.ly/1iNuOKJ

Porter, S. R. (2007). A closer look at faculty service: What affects participation on committees? The Journal of Higher Education, 78(5), 523-541.

Reddick, R. J. (2011). Intersecting identities: Mentoring contributions and challenges for Black faculty mentoring
Black undergraduates. Mentoring \& Tutoring: Partnership in Learning, 19(3), 319-346.

Rith, C., \& Dubberly, H. (2006). Why Horst W. J. Rittel matters. Design Issues, 23(1), 72-91.

Rittel, H. W. J. \& Webber, M. M. (1973). Planning problems are wicked. Retrieved from: https://bit.ly/2YbUFJn

Rudolph, F. (1962). The American college and university: $A$ history. University of Georgia Press.

Samuels, R. (2017). Introduction: Teaching critical university studies. Radical Teacher 6, 1-4, 56.

Shearer, A. (2015). Abduction to argument: A framework of design thinking. Landscape Journal, 34(2), 127-138.

Simon, H. A. (1996). The sciences of the artificial (3rd ed). Cambridge, MA: The MIT Press.

Slaughter, S. \& Rhoades, G. (2000). The neo-liberal university. New Labor Forum, 6, 73-79.

Smiley, J. (1995). Moo. New York: Anchor Books.

Steffen, H. (2017). Inventing our university: Student-faculty collaboration in critical university studies. Radical Teacher, 108, xx-xx.

Thelin, J. R. (2011). A history of American higher education. JHU Press.

Trustees of Phillips Exeter Academy. (2018). The Harkness gift. Retrieved from: https://www.exeter.edu/aboutus/harkness-gift

Veysey, L. R. (1970). The emergence of the American university. University of Chicago Press.

Vitasek K. (2014). Churchman, Rittel, and Webber: The 'wicked' problem. The Academics of Sourcing. Retrieved from: https://futureofsourcing.com/churchman-ritteland-webber-the-\%E2\%80\%9Cwicked\%E2\%80\%9Dproblem.

Waks, L. J. (Ed.). (2015). Listening to teach. Albany, NY: SUNY Press.

Whelan, A. (2016). Agnosis in the university workplace. Australian Universities Review, 58(2), 51-58. 